\title{
O LUGAR DA CRIANÇA NA PESQUISA SOBRE A INFÂNCIA: ALGUNS POSICIONAMENTOS NA PERSPECTIVA DA TEORIA HISTÓRICO- CULTURAL
}

Suelly Amaral Mello ${ }^{1}$

\section{Resumo}

Ao defender a necessidade da voz das crianças nas pesquisas sobre a infância, busco, neste artigo, um argumento essencial da abordagem histórico-cultural do desenvolvimento humano: a compreensão de que ao se relacionar com a cultura, a criança atribui um sentido pessoal ao que conhece. Esse sentido conforma a concepção com a qual a criança, a partir daí, se dirige à cultura para novas apropriações e aprendizados que são promotores do desenvolvimento de sua consciência em processo de formação. Em outras palavras, esse sentido produzido pela criança condiciona seus processos de aprendizagem. Desse ponto de vista, parece fundamental que a pesquisa sobre a criança pequena contemple sua participação também como informante e não apenas como objeto desse processo.

Palavras-chave: Abordagem histórico-cultural; concepção de criança; pesquisa com criança pequena.

\footnotetext{
${ }^{1}$ Doutora em Educação pela Universidade Federal de São Carlos/UFSCar e Mestre em Educação pela mesma universidade. Graduação em Letras Modernas pela Universidade Estadual Paulista. Atualmente é professora do Programa de Pós-Graduação em Educação da Universidade Estadual Paulista/Unesp, Faculdade de Filosofia e Ciências/campus de Marília e vice-líder do grupo de pesquisa "Implicações Pedagógicas da Teoria Histórico-Cultural”.
} 
É nova, entre nós, a preocupação em ouvir as crianças nas pesquisas em educação e novo, também, o enfrentamento desse desafio. De fato, essa nova atitude não depende de uma decisão simples. Ao contrário, a atitude de ouvir as crianças e considerá-las - seja em nossas práticas pedagógicas, seja em nossas pesquisas - só é possível à medida que superamos o conceito de criança que por longo tempo orientou nosso pensar e agir na educação das crianças, especialmente das crianças pequenas. $\mathrm{O}$ conceito de criança como alguém incapaz de aprender até atingir certo nível de desenvolvimento nasceu de uma visão adultocêntrica de criança pequena que a caracterizava predominantemente de um ponto de vista negativo, destacando suas incapacidades em comparação com os adultos, a limitação de sua experiência, a insuficiência de seus conhecimentos, a incapacidade de pensar logicamente, de controlar sua própria conduta. Como lembra Vygotsky (1995), um ponto de vista negativo que nada nos diz das peculiaridades positivas que diferenciam a criança do adulto. Essa concepção foi, por muito tempo, sustentada por uma psicologia do desenvolvimento que procurava explicar pela herança biológica as qualidades humanas que, hoje sabemos, são sociais e históricas. E, seguindo a lógica do senso comum e da vida cotidiana, esse conceito de criança foi, aos poucos, se generalizando para o conjunto das crianças e tomou a escola como um todo. Incapazes não seriam apenas as crianças pequenininhas, mas as crianças de um modo geral. Ainda que, do ponto de vista do discurso, não vejamos essa concepção regularmente anunciada, um olhar para as práticas educativas e para as práticas de pesquisa envolvendo crianças denuncia a concepção de criança como alguém que não sabe e não é capaz de aprender - concepção que nega, vale dizer, a própria função anunciada da escola.

Essa incapacidade da criança refere-se, de um modo geral, a todas aquelas atividades que valoramos como coisas de gente grande: por isso nossas crianças não são 
- senão em práticas pedagógicas consideradas alternativas, inovadoras e, por isso, diferenciadas - chamadas a participar do planejamento de festas ou outras atividades que as envolvem, nem das atividades de rotina na escola; não são chamadas a avaliar processos vividos, a participar da organização da sala ou da solução de problemas em que estão envolvidas. Em não raras situações, nem reconhecemos sua produção. Falo de situações em que os/as professores/as - quando permitem que a criança realize uma atividade pedagógica proposta - se permitem retocar a produção infantil para ficar com melhor aparência. Da mesma forma, não são raras as situações em que os/as professores/as praticam pela criança ações que consideram difíceis que esta realize com o resultado esperado, ainda que sejam ações propostas pelos/as próprios/as professores/as. Em todas essas situações, não se trata de a criança não saber fazer, mas de os/as professores/as não valorizarem sua produção, não perceberem essas produções como momentos específicos da apropriação e da objetivação da cultura que as crianças vão fazendo ao longo da infância, como formas livres de experimentação com materiais e como expressão valiosa da interpretação que a criança faz daquilo que vive, experimenta e aprende. Em outras palavras, como a maneira especifica da criança produzir teoria sobre o mundo que a rodeia e as situações que vivencia e expressá-las.

Sem uma compreensão de que as qualidades humanas são histórica e socialmente aprendidas e, portanto, precisam ser vivenciadas ativamente pela criança, acabamos por impedir sua participação em atividades que ensinam diferentes capacidades práticas, intelectuais e artísticas e que iniciam a formação das primeiras ideias, sentimentos e hábitos morais, os traços de caráter, enfim, os fundamentos da personalidade e da inteligência.

Por isso, a atitude de desconsiderar a criança ao falarmos sobre ela tem sido uma marca dos métodos de investigação sobre a infância. 
Krupskaya, falando das tarefas da educação infantil, em 1932, já defendia a necessidade de observarmos as crianças pequenas se quisermos conhecê-las e respondia criticamente àqueles que acusavam essa forma de estudar as crianças como uma transgressão dos princípios revolucionários e um desvio em direção ao empirismo:

Por acaso um médico pode aprender a curar se não conhece a enfermidade? Por acaso podemos educar as crianças se não conhecemos as particularidades da idade e do meio em que crescem? (KRUPSKAYA, 1979, p. 249).

Também Vygotsky, nessa mesma época, já apontava a necessidade de uma nova perspectiva na pesquisa com as crianças:

Se tivéssemos que determinar de maneira geral quais exigências básicas se colocam ao problema do desenvolvimento das investigações modernas, a resposta seria que o fundamental é o estudo das peculiaridades positivas do comportamento infantil (VYGOTSKY, 1995, p. 141).

Para tanto, como sugere a citação, é preciso superar o conceito de criança que vem orientando o pensar e o agir nas práticas pedagógicas e nas práticas de pesquisas sobre a infância. Tal superação envolve a apropriação de uma concepção do desenvolvimento infantil que questione as compreensões simplistas que abrangem este desenvolvimento à semelhança dos processos de crescimento das plantas e dos animais, como processos naturais, isto é, biologicamente determinados, acontecendo por acúmulo quantitativo no nível do indivíduo e não na relação social. Ainda conforme Vygotsky,

a tarefa que se coloca hoje para a psicologia é a de captar a peculiaridade real da conduta da criança em toda sua plenitude e riqueza de expansão e apresentar o positivo de sua personalidade. Entretanto, o positivo só aparece se modificarmos radicalmente a concepção sobre o desenvolvimento infantil e se compreendermos que se trata de um complexo dialético que se caracteriza por uma complicada periodicidade, pela desproporção no desenvolvimento das diferentes funções, pelas metamorfoses ou transformação qualitativa de umas formas em outras, um entrelaçamento complexo de processos evolutivos e involutivos, pelo complexo entrecruzamento de fatores externos e internos, um complexo processo de superação de dificuldades e de adaptação (VYGOTSKY, 1995, p.141). 
Desse ponto de vista, portanto, a prática pedagógica e a prática de pesquisa, tanto com crianças como sobre crianças, precisam ser fundamentadas por uma concepção de desenvolvimento infantil que considere a criança como capaz de estabelecer relações com os outros e com o mundo desde o nascimento e que conceba essas experiências vividas socialmente como processos de aprendizagem responsáveis por impulsionar a formação e o desenvolvimento das qualidades humanas na infância.

Para a teoria histórico-cultural, inverte-se a relação entre desenvolvimento e aprendizagem que nos acostumamos a pensar a partir das velhas concepções da psicologia que, de um modo geral, nos foram ensinadas. Desse ponto de vista, a compreensão de que o desenvolvimento aconteceria naturalmente - uma vez que biologicamente determinado - cede lugar à concepção da materialidade dos processos psíquicos. Com isso, passamos a compreender que o desenvolvimento decorre de processos de aprendizagem, condicionado socialmente pelas experiências vividas. Essa compreensão impulsiona uma mudança na concepção de criança que passa a ser concebida como capaz de aprender desde pequenininha, inicialmente com as experiências perceptivas que permitimos que viva e, a partir daí, vai formando para si qualidades humanas, num complexo processo dialético que envolve, em última instância, três elementos essenciais: os objetos da cultura oferecidos à criança; a atitude mediadora dos adultos que cuidam e educam a criança - ou seja, a concepção de criança desses adultos que medeiam a relação da criança com a cultura - e a própria ação da criança. Essa ação da criança se concretiza, como afirma Vygotsky na citação acima, numa complicada periodicidade, envolve a transformação qualitativa de umas formas em outras, resulta de um entrelaçamento complexo de processos evolutivos e involutivos, de um complexo entrecruzamento de fatores externos e interno, de 
superação de dificuldades e de adaptação. E essa complexidade precisa ser compreendida pelos adultos que educam a criança.

Parece importante enfatizar o fato de que esse complexo processo de humanização é, na verdade, sinônimo de processo de educação, uma vez que é sempre mediado, em última instância, por um parceiro mais experiente. Deste ponto de vista, vale lembrar Poddiakóv (1987), para quem o conhecimento anterior acumulado pela criança constitui-se, em muitas circunstâncias, em mediador de novos acessos das crianças em direção ao que ela ainda não conhece. No entanto, esse processo de autodesenvolvimento do pensamento ou de descoberta do desconhecido a partir do que já é conhecido não garante o acesso ao conjunto da cultura histórica e socialmente acumulada. Conforme Leontiev (1978), citando uma imagem utilizada por Pieron para destacar o lugar do educador nos processos de educação:

Se o nosso planeta fosse vítima de uma estranha catástrofe que só poupasse as crianças pequenas e na qual pereceria a população adulta, isso não significaria o fim do gênero humano, mas a história seria inevitavelmente interrompida. Os tesouros da cultura continuariam a existir fisicamente, mas não existiria ninguém capaz de revelar às novas gerações o seu uso. As máquinas deixariam de funcionar, os livros ficariam sem leitores, as obras de arte perderiam sua função estética. A história da humanidade teria de recomeçar (LEONTIEV, 1978, p. 272).

Nesse processo de educação do qual resulta a formação das qualidades humanas - de apropriação de qualidades criadas pelos homens e mulheres que nos antecederam ao longo da história -, a criança tem um papel ativo. Considerando os três elementos constitutivos do processo de educação na escola - a cultura como fonte das qualidades humanas historicamente acumuladas, os professores como mediadores do acesso das crianças à cultura e a própria criança -, Vygotsky (1994) afirma em relação aos dois primeiros elementos que:

não é nenhum dos fatores em si (se os considerarmos sem relacioná-los com a criança) o que determina como eles influenciarão sobre o futuro do 
desenvolvimento da criança; mas os próprios fatores percebidos através do prisma da experiência emocional (parezhivaniya) da criança.

(...) Em outras palavras, como a criança se informa, interpreta e se relaciona emocionalmente com um certo acontecimento: é esse prisma que determina o papel e a influência do meio sobre o desenvolvimento (VYGOTSKY, 1994, p. 341 - tradução nossa).

No processo em que se inteira do mundo e aprende, a criança atribui sentido aos significados sociais de que se apropria. Desse ponto de vista, é ativa e esse processo acontece desde que nasce. Conforme Vygotsky (1996), o primeiro ato humano de amamentação começa a criar uma nova necessidade no recém-nascido. Essa nova necessidade não é biológica, não é essencial à sua sobrevivência, mas é social, aprendida: a necessidade da relação com o outro. E a partir daí, novas necessidades não param de se criar na criança pequenininha como resultado de sua experiência social.

Essa nova concepção de criança - capaz de estabelecer relações que paulatinamente vão se ampliando e se tornando mais complexas com o mundo que a rodeia - desperta no educador e no pesquisador da infância a necessidade de conhecê-la em suas peculiaridades positivas. Como é que essa nova criança que emerge de um novo olhar se relaciona com o mundo e aprende nas diferentes idades?

Ao mesmo tempo e na mesma perspectiva, se a cultura - o meio social e histórico - e o próprio mediador influenciam o desenvolvimento infantil por meio da relação que a criança estabelece com eles, relação essa que é condicionada pela vivência - pela experiência emocional e pelas experiências anteriores da criança -, sua expressão é condição essencial dessa nossa nova compreensão. Se a apropriação que a criança vai fazendo do mundo não é linear, mas condicionada por sua experiência emocional, pela atividade que realiza em relação ao objeto da cultura com que se relaciona, nosso conhecimento de como esse processo se efetiva depende essencialmente de conhecermos os sentidos que cada criança vai atribuindo aos elementos da cultura que vai conhecendo e do qual vai se apropriando a partir da maneira como os interpreta, 
como se inteira deles, de como se relaciona emocionalmente com eles. E a condição para conhecer esses sentidos é a própria expressão das crianças.

Para a teoria histórico-cultural, o processo de formação dos seres humanos se constitui na relação dinâmica entre os processos de apropriação e de objetivação. Em outras palavras, não apenas o processo de apreender a cultura, mas também aquele em que expressamos essa apropriação que vai sendo feita da cultura constituem, ambos, a dinâmica essencial do processo de humanização ou de educação. Entendemos, com isso, que a expressão é condição essencial do processo de formação das qualidades humanas nas crianças e, como tal, constitui conhecimento essencial do trabalho de professores e pesquisadores que querem avaliar o sentido de seu trabalho. Da mesma forma, a objetivação - ou seja, a expressão da criança por meio das atividades que realiza - é objeto de estudo do pesquisador que queira conhecer a criança e seus processos de desenvolvimento. Mais que conhecer as objetivações infantis e analisá-las com uma lógica de pensar e agir própria dos adultos, será fundamental ao pesquisador e ao professor compreender os sentidos, os motivos das crianças para as atividades que realizam. Esses sentidos não se mostram na aparência dos fatos observados, mas precisam ser procurados na forma como as crianças pensam e compreendem, em cada etapa de sua vida, as atividades que realizam, as situações que vivenciam. Adentrar nessa lógica infantil a partir do que a criança faz e de como faz é condição para compreender o processo de desenvolvimento de sua personalidade.

Desse ponto de vista, a partir da teoria histórico-cultural, temos uma única certeza: os processos psíquicos têm origem material, são vividos coletivamente antes de serem internalizados pelas crianças. Para além disso, somos desafiados a descobrir, por meio da pesquisa, como as crianças elaboram o que vivem e testemunham. Como se inteiram, interpretam e organizam para si os elementos da cultura, isto é, os objetos 
materiais e não materiais, os instrumentos, a língua, as diferentes linguagens, os hábitos, os costumes, os valores, as técnicas, a ciência, a arte, a filosofia.

Entendendo, com a teoria histórico-cultural, que a criança, ao se relacionar com a cultura, atribui um sentido pessoal ao que conhece, e esse sentido conforma a concepção com a qual a criança, a partir daí, se dirige à cultura para novas apropriações e aprendizados que são promotores do desenvolvimento de sua consciência em processo de formação, parece fundamental que a pesquisa sobre a criança contemple esta também como informante e não apenas como objeto desse processo.

As múltiplas linguagens - as diferentes formas de expressão -, e não apenas a linguagem oral, podem facilitar nosso acesso às formas de pensar na infância, à lógica das explicações dos fatos, dos fenômenos, das relações em diferentes momentos da formação e apropriação dessa lógica. Ao mesmo tempo, podemos tomar sua expressão por meio de múltiplas linguagens como ponto de partida para uma compreensão que pode ser também expressa pela linguagem oral, num formato semelhante a uma entrevista com roteiro aberto em que o pesquisador dialoga com a criança sobre suas teorias de explicação/compreensão da realidade que vai conhecendo.

Então, se consideramos que a criança é capaz de expressar o que aprende com aquilo que vive, e, mais ainda, que sua objetivação faz parte do processo de apropriação, procuramos conhecer esse processo. Quando se considera que o processo de pensar é aprendido, a forma como a criança pensa passa a ser objeto do interesse dos pesquisadores e dos professores.

Em diferentes momentos de sua obra, Vygotsky enfatiza a importância das formas de expressão das crianças. Discutindo a situação da criança pequenininha, o autor destaca a contradição entre sua máxima dependência e, portanto, sua máxima necessidade do outro - sua máxima sociabilidade - e a ausência dos meios 
fundamentais de comunicação sob a forma de linguagem humana reconhecida. Essa característica da situação social do desenvolvimento da criança pequenininha confere a esse momento da vida da criança uma peculiaridade:

A organização de sua vida lhe obriga a manter uma comunicação máxima com os adultos, mas esta comunicação é uma comunicação sem palavras, em geral silenciosa, uma comunicação de caráter totalmente específico (VYGOTSKY, 1996, p. 286).

Ao discutir a apropriação da linguagem escrita pelas crianças, Vygotsky aponta que, antes de se fazer escrita, a expressão tem uma longa história que começa com o gesto. Para o autor, a tentativa frustrada de alcançar um objeto distante produz um movimento que, interpretado pelo adulto, passa a ter um sentido de gesto indicativo. Dessa forma, mediado pela compreensão do adulto, o gesto passa a indicativo da vontade da criança, passa a ser uma forma de sua expressão. Depois do gesto, vêm a fala, o desenho e as múltiplas linguagens plásticas, corporais, musicais e o faz-de-conta. E por meio de todas essas linguagens, as crianças expressam a forma como interpretam o que conhecem e as experiências que vivem.

Portanto, pensando a criança e seu desenvolvimento do ponto de vista históricocultural, superamos a velha concepção de criança incapaz que povoa nosso pensar e agir docentes - o que deve promover um conjunto de transformações na escola da infância. Para isso, no entanto, essa nova concepção de criança capaz - e de aluno capaz, no ensino fundamental - precisa ultrapassar o nível do anúncio e incorporar-se às práticas docentes. Não basta saber que teorias defendem e que pesquisas mostram que a criança é capaz de aprender desde que nasce - dentro da especificidade de suas formas de relacionar-se com o mundo; tampouco basta anunciar que a aprendizagem é o fator que move o desenvolvimento. Para incorporar essa concepção às práticas, nós, professores, precisamos viver experiências que demonstrem o fazer independente das crianças e suas peculiaridades positivas, as capacidades formadas e em formação nas diferentes idades. 
Promover atividades livres e diversificadas em grupos num espaço em que a cultura esteja presente sob a forma de objetos diversificados pode nos iniciar nessa nova cultura. Objetos diversificados que vão desde os naturais à sucata; dos mapas aos materiais de arte, passando pelos livros infantis e demais portadores de texto; dos objetos eletrônicos aos retalhos de pano; objetos deste e de outros tempos, deste e de outros lugares constituem um acervo que provoca a atividade independente e coletiva das crianças. Ao perceber as crianças como capazes de se organizarem para experimentar com os objetos, poderemos passar a considerá-las capazes de participar também dessa nova organização do espaço da escola que procura contemplar a riqueza da cultura acumulada historicamente; capazes também de participar da coleta de novos materiais. Poderemos convidá-las para participar do trabalho diário de arrumação da sala (Russo, 2005) e possibilitar a sugestão de novas formas de organização do tempo e do espaço, bem como a utilização de novos espaços e novos materiais. Nessa perspectiva, passamos a relações mais horizontais e solidárias, sem prejuízo do acesso ao conhecimento. Ao contrário, esse acesso ao conhecimento histórica e socialmente acumulado pode se fazer mais intenso porque mais focado em necessidades das crianças e também naquelas que vão sendo criadas nas crianças - papel essencial da escola de um modo geral e que, também na educação das crianças pequenas, tem como desafio essencial a promoção do encontro das pessoas de qualquer idade com a cultura, especialmente aquela a que as pessoas não têm acesso em casa, na vida cotidiana.

A partir daí, teremos o espaço da sala e da escola organizado para contemplar a cultura histórica e socialmente acumulada e também para conter as interpretações dessas experiências de conhecimento expressas pelas crianças, as quais chamamos culturas infantis. Mais que isso, se passarmos a considerar as crianças como capazes de aprender o que ainda não sabem, passaremos a organizar o espaço da escola também para garantir 
o acesso de todas as crianças a todos os materiais em tempo integral e não apenas naqueles momentos em que o professor julga adequados.

Esse novo conceito de criança e de como se dá seu desenvolvimento também promove mudanças radicais na atividade da criança, no lugar que esta ocupa na escola infantil e na escola de ensino fundamental. Ativa no processo de aprender, quando interpreta e atribui sentido ao que vive, a criança aprende o que exercita na atividade que realiza (Leontiev, 1998). Desse ponto de vista, essa criança capaz que vemos emergir da abordagem histórico-cultural do desenvolvimento humano precisa realizar em relação aos objetos de que se apropria - e das funções psíquicas e capacidades incrustadas nesses objetos - a função adequada para a qual o objeto foi criado, ou seja, precisa exercitar ela mesma as funções que queremos que aprenda: aprende a pensar participando da resolução de problemas, aprende a falar relatando histórias e fatos vividos, trocando teorias interpretativas do mundo com seus pares e com os/as professores/as, aprende a avaliar participando de processos coletivos de avaliação, aprende a planejar participando do planejamento das atividades. Para tudo isso, no entanto, é condição essencial a concepção de criança capaz de aprender, ou seja, capaz de inteirar-se de, de relacionar-se com, de interpretar e atribuir um sentido, de elaborar uma teoria interpretativa ao que vive e vê.

Faz muito pouco tempo que as crianças brasileiras passaram a viver parte de sua infância - muitas já vivem a maior parte da infância - em espaços coletivos e extradomésticos de educação e cuidado. Desde que começamos a pesquisar as crianças nas instituições de educação infantil - ou, em outras palavras, desde que começamos a pesquisar o processo de humanização em processos de educação coletiva com crianças pequenas -, descobrimos muitos preconceitos, muitas ideias e concepções equivocadas e estigmatizadoras sobre a criança e a infância que orientavam nosso pensar e agir. 
Apenas nos iniciamos nesse processo de necessária revisão de nossas práticas na escola da infância. Do ponto de vista histórico-cultural, esse processo de conhecimento deve ser trilhado com um olhar orientado por uma fundamentação teórica que explique o processo educativo em sua materialidade, o que envolve profundamente a atividade docente e a retira do marasmo da naturalização dos processos.

Esse caminho, no entanto, não precisa ser solitário na escola da infância e do ensino fundamental: a criança pode ser a companhia solidária nesse processo de recriação da escola na direção de fazê-la um exercício de formação de seres humanos cada vez mais humanizados pelo acesso ilimitado à cultura.

\title{
THE PLACE OF CHILDREN IN RESEARCH ON CHILDREN: SOME PLACEMENTS IN THE PERSPECTIVE OF HISTORIC-CULTURAL THEORY
}

\begin{abstract}
Defending the importance of the child's voice in research on childhood, I bring in this article, an essential argument of the historical-cultural approach to human development: the comprehension that when relating to culture, the child gives a personal sense to what she knows. This meaning shapes the new approaches the child, from there on, does to culture for new appropriations that promote development of conscience. In others words, this sense produced by the child affects her learning processes. From this standpoint, it seems imperative that research on infant also contemplates their participation as informants and not just as an object of this process.
\end{abstract}


Keywords: Cultural-historical approach; child conception; research with small children.

\section{Referências}

ABBAGNANO, Nicola. Dicionário de Filosofia (Tradução Alfredo Bosi). 2. ed. São Paulo: Martins Fontes, p. 841-844,1992.

ARIÈS, Philippe. A História Social da Criança e da Família. Rio de Janeiro: LTC, 1981.

KRUPSKAYA, N. K. Acerca de la educación pré-escolar. Havana: Editorial Pueblo y Educación, 1979.

LEONTIEV, A. N. O Homem e a Cultura. In O Desenvolvimento do Psiquismo. Lisboa: Livros Horizonte, 1978.

LEONTIEV, A. N. Contribuição para uma teoria do desenvolvimento da psique infantil. In: VYGOTSKY, LURIA e LEONTIEV. Linguagem, desenvolvimento e aprendizagem. São Paulo: İcone; Editora da USP,1998

MELLO, Suely Amaral. Enfoque histórico cultural: em busca de suas implicações pedagógicas para a educação de 0 a 10 anos. In: Anais da I Conferência Internacional: o enfoque histórico cultural em questão. 2006. p.89-102.

MELLO, Suely Amaral. Linguagem, consciência e alienação: o óbvio como obstáculo ao desenvolvimento da consciência crítica. Marília: Unesp, 2000.

MELLO, Suely Amaral. A teoria, na prática, é outra? Um estudo sobre as mediações teoria/prática na ação educativa. São Carlos, 1981. Dissertação de Mestrado (Universidade Federal de São Carlos).

MELLO, Suely Amaral. O processo de aquisição da escrita na educação infantil: contribuições de Vygotsky. In: FARIA, Ana Lucia Goulart \& Mello Suely Amaral (Orgs.) $O$ mundo da escrita no universo da pequena infância. Campinas, SP: Autores Associados, 2005. (Coleção Polêmicas do nosso Tempo).

PODDIÁKOV, N. Sobre o problema do desenvolvimento do pensamento nos preescolares. In DAVIDOV, V. e SHUARE, M. (orgs) - La Psicología Evolutiva y Pedagógica en la URSS (Antologia). Moscou: Editorial Progresso, 1987.

RUSSO, D. De como ser professor sem dar aulas na escola da infância. In: FARIA, A. L. Goulart de, e MELLO, S. A. (orgs) Territórios da Infância: linguagens, tempos e relações para uma pedagogia para as crianças pequenas. Araraquara, SP: Junqueira e Marin, 2007. 
VYGOTSKY, L. S. Obras Escogidas vol. III. Madrid: Madrid: Centro de publicaciones del MEC y Visor Distribuiciones, 1995.

VYGOTSKY, L. S.; LURIA, A. R.; A aprendizagem e desenvolvimento intelectual na idade escolar. In: VYGOTSKY, L. S.; LURIA, A. R.; LEONTIEV, A. N., Linguagem, desenvolvimento e aprendizagem. São Paulo: Ícone, 2001.

VYGOTSKY, L. S. The Problem of Environment. In: VALSINER, J. e VEER, R.van der. The Vygotsky Reader. Cambridge e Oxford: Blackwell, 1994.

VYGOTSKY, L. S. - O primeiro ano. In: Obras Escogidas. vol. IV. Madrid: Visor, 1996.

Data de recebimento: $24 / 07 / 2010$

Data de aceite: 13/09/2010 